Monatsschrift für Geburtshülfe und Gynäkologie 1905;22:296

\title{
Personalien und Tagesnaehrichten
}

Am 18. Jun ist der Direktor der Provinzial-Hebammenlehranstalt, Herr Medizinalrat Dr. Toporski-Posen, aus dem Leben geschieden.

Ein Schiiler von Fritsch, hat er sich mit grosser Energie der Auf-gabe unterzogen, das Hebammenlehrinstitut seiner Heimatprovinz auf eine moderne Höhe zu heben. Es ist ihm vergönnt gewesen, einen sehr hervor-ragenden Neubau aaszuführen, in welchem er neben dem geburtshülflichen aueb das gynäkologische Matei"ial entwickeln konnte.

Toporski war ein überaus eifriger Lehrer, der es verstanden hat, einen Kreis von Assistenten um sicb zu versammeln, welche mit grosser Verehrung an ihm hingen. Als Praktiker überaus geschätzt, ist er literarisch selbst nicht hervorgetreten. Sein Andenken wird bei alien, welche ihm nahe standen, in Ehren bleiben!

In Lausanne hat sich Dr. A. Weith als Privatdozent für Gynäkologie habilitiert, in Petersburg am klinischen lnstitut für Frauen die DDr. N. Kanne-giesser und A. Sitzinsky für Geburtshülfe. 